\title{
Academic Writing Within An Online Learning Environment: Assessing The Impact Of Peer Evaluation On Lesson Planning, Execution \& Assessment
}

Karen Sanderson Cole, University of the West Indies, Trinidad

Danielle Watson, University of the West Indies, Trinidad

\begin{abstract}
Peer evaluation, as a learning strategy, is commonly used among educators in an attempt to promote higher performance goals and improved teaching and learning outcomes through the sharing of complementary proficiencies for a familiar intent. It is commonly viewed as a technique for 'raising the bar' through exposing educators to alternative perspectives. Within the online learning environment, there is a high degree of isolation among educators involved in the delivery of the same course. Although individuals interact in established teacher forums about administrative issues, a forum is not provided where interaction about teaching content, delivery and conceptualization of critical concepts can be explored and discussed. As such, the provision of a forum for collaboration among peers involved in different aspects of course delivery within the online learning environment is believed to address the issue of isolated instruction while also providing support and evaluation as to the effectiveness of teaching strategies employed. The aim of the research is to investigate the impact of an established peer partnership between 14 colleagues working in pairs geared towards assessing feedback and discussions on lesson planning, execution and assessment processes. It seeks to ascertain its usefulness as a strategy to be incorporated into the teaching of English for Academic Purposes within an online learning environment. The study seeks to provide actionable direction for peer evaluation and collaboration, as a teaching and learning tool, through the mapping, assessing and evaluation of the processes involved.
\end{abstract}

Keywords: Peer Evaluation; Collaborative Teaching; e-learning

\section{INTRODUCTION}

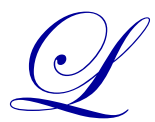

esson planning and execution are integral components of the teaching and learning process. It is through the planning process that learning facilitators examine the content to be explored, determine learning objectives and devise strategies to meet the requirements of the lesson, while also considering the variety of learners for which the lesson is designed. At this stage, educators explore possible strategies to enhance learning through the provision of an appropriate learning environment. The plan is executed in the learning environment where learners are exposed to content and engaged in an attempt to meet set objectives. Although planning and execution of a lesson necessitates a degree of knowing and responsibility on the part of the practitioner, it is primarily the extent to which learning takes place as well as the ability to reflect on possibilities for improvement of one's practice to enhance learning, which defines 'good' instruction. Instruction is influenced, to a large extent, by individuals' knowledge frameworks, beliefs and ideologies about knowledge acquisition as a component of the teaching and learning paradigm.

English for Academic Purposes is a compulsory level one course for students entering the University of the West Indies. In its online form, it caters to an average of 500 across the Caribbean. In courses such as this one, at 
the tertiary level, staffing requirements vary and, in most instances, require a slate of instructors to provide instruction to sub-groups of students. Although all individuals involved in the delivery of a course have access to course outlines and guidelines for content to be explored within respective sessions, a forum is rarely provided to process the extent to which there is a degree of parity among them as well as an opportunity to assess individuals' conceptualization of respective topics. Where confusion exists about content or there is the selection of unwise methods of delivery, the extent to which teaching impacts learning is significantly affected. As such, students are likely exposed to varying interpretations of content and instruction, whereas they are assessed using the same instruments. The need for a further degree of parity is further demonstrated where students are assessed by individuals with whom their teaching and learning experience was not directly shared, thus the possibility of being assessed, based on criteria to which they were never exposed, exists.

An investigation into the merit of incorporating peer evaluation offers an alternative to self-contained instruction and the notion of 'one teacher teaching' (Francis and Buckley, 1999). Peer evaluation is not a new concept to the field of higher education. It is usually employed as a method of formative and summative assessment for teaching staff and students alike. In recent years, beginning with the work of Showers and Joyce (1980), the concept of peer coaching has crept into the literature. The term "coaching" foregrounds the idea of an ongoing, collaborative relationship where one person works with or trains another person over an extended period of time. As Waller (2004) observes, informal means of evaluating faculty have always existed. This holds true for the Caribbean region as well.

In the field of higher education in the Caribbean, peer coaching is often an informal process, with heavy emphasis being placed on student course evaluations and exam performance as indicators of teacher effectiveness. Most of the available literature comes from the U.S and the developed world. The recent introduction of the Masters in Higher Education at the University of the West Indies, St Augustine, has offered teaching practitioners a renewed drive for engaging meaningful opportunities for exploring peer coaching within a Caribbean context. Although peer evaluation is used for a variety of reasons within the academic sphere, the study deploys it specifically as a tool to enhance teachers' performance within the context of teaching and learning. The research explores the merit of cognitive coaching strategies as a tool to enhance the quality of instruction within a specific programme - English for Academic Purposes - a compulsory level one course for students entering the University of the West Indies. It seeks to disprove the notion of the classroom as the teacher's domain where knowledge is imparted by a single educator from a single viewpoint. It proposes to discover an actionable direction for the inclusion of peer evaluation into the teaching of large academic writing courses through the exploration of its impact on the processes of lesson planning and execution.

\section{A FOUNDATION FOR PEER EVALUATION/COACHING WITHIN THE ONLINE ENVIRONMENT}

Dalton and Moir (1991) characterize peer coaching as the development of effective joint ventures geared towards the fostering of constructive dialogue, which leads to the interrogation and enhancement of one's practice. It is premised on the creation of a forum where practitioners within the same field can share ideas and experiences with the aim of enriching the practice of others. The assumed merit of implementing such a strategy within the online academic writing environment holds true, as interaction within established staff forums is primarily centered around administrative matters and occurs mainly between coordinator and e-tutor. The coordinator's presence is 'omniscient' in that an awareness of what strategies are implemented by all e-tutors is had. The e-tutors' knowledge is limited to their respective forums with no knowledge of strategies being employed by colleagues. As such, established partnerships not only allow for a sense of companionship and support from colleagues, they also promise to improve collegiality and enhance practice (Joyce \& Showers, 1995; Tschantz \& Vail, 2000). Literature on the subject also points to the benefits of exchanging teaching methods and materials (Vacilotto \& Cummings, 2007).

\section{Benefits of Peer Evaluation}

Stacey and Wilson (2004) outline several successful models for the use of localized peer support where faculty members are appointed to provide peer support to newer faculty members engaged in adapting new strategies for teaching online. While several approaches may be implemented for different outcomes, the approach taken for this study highlights the implementation of peer interaction as an opportunity to foster collaboration, share 
expertise, and learn from other academics within the field. Peer evaluation, as a teaching tool, provides a forum for teaching practitioners to pool their capacities and strategies in an attempt to improve content, approaches to delivery, and, ultimately, maximize learning through the creation of teaching teams (Francis and Buckley, 1999). It is believed to promote an environment of purposeful cooperation where varying views on the same topic can be shared, discussed, and analyzed to identify viable variables. It disproves the concept of a single model template for instruction and assessment as the strengths of practitioners are combined and their weaknesses remedied. In fact, Cordingley, Bell et al (2003), argue that benefits of peer collaboration include greater confidence, development of enthusiasm and enhanced beliefs among teachers of their ability to make a difference. For Francis and Buckley (1999), the creation of teaching teams through peer evaluation encourages practitioners to reflect on their practice by examining what, why, and how they teach in an attempt to do it better. Negotiated Order Theory as proposed by Gray (1989) sees collaboration as a process negotiated among stakeholders. It consists of four basic steps: 1) choosing colleagues or team members, 2) dividing the labor, 3) establishing work guidelines, and 4) terminating collaboration.

Within the online learning environment, the responsibility of ensuring/facilitating student learning falls largely on the educator. As such, educators are required to devise strategies to ensure the learning environment created is effective. What is learnt is largely dependent on the facilitator's own knowledge base as well as the manner in which content is introduced, explored, and interpreted. Figure 1 depicts the assumed experiences of an individual teacher within the learning environment.

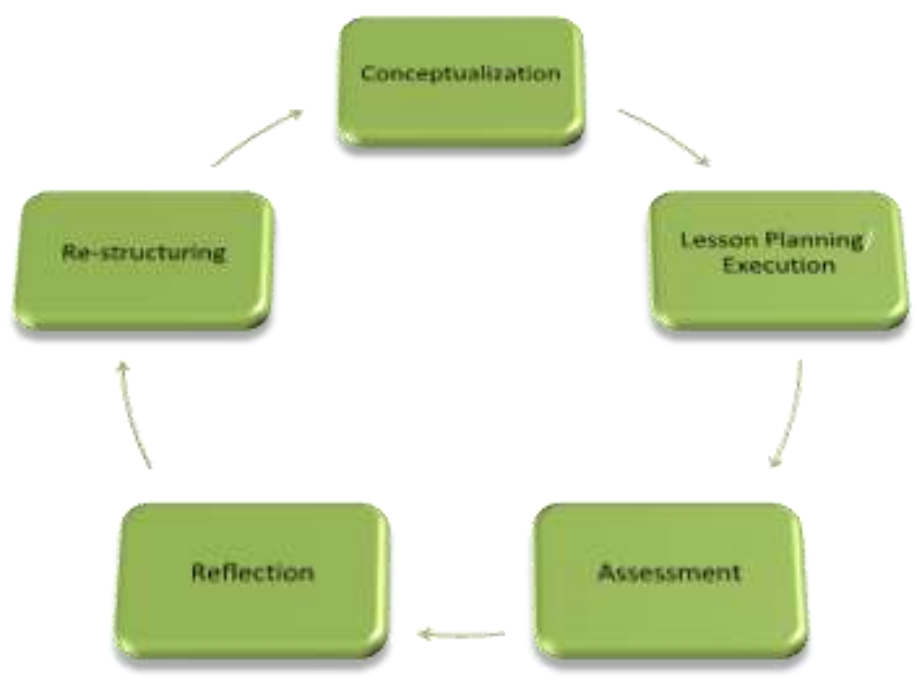

Figure 1: Experiences of Teacher in Learning Environment

Teaching done in this manner, while necessary within some spheres, disallows the formation of educational communities supported by collaboration. The provision of a peer support team connotes the merger of two individuals' experiences. In keeping with the perspectives of Roschelle and Pea (1999), the development of peer teams propels positive changes towards collaborative representations, advanced socio-cognitive scaffolding, and tools that foster self-improving communities. In essence, this provides a forum for discussion, sharing, constructive critiquing, teaching, learning, re-conceptualization and, essentially, improved teaching and learning. The peer team allows from movement from the delivery of an individualized interpretation to the delivery of content expressive of diverse voices underpinned and validated by collaboration and meaningful discussion. In essence, it encourages staff to take control of their own personal development (Stuckey, Lockyer \& Hedberg, 2001) while also increasing accessibility and communication opportunities among staff. 


\section{Peer Evaluation and the Virtual Academic Writing Classroom}

In order to gauge the implementation and implications of peer evaluation within the online environment, necessary insight into existing research about online teaching and collaboration must be examined. The role of the online educator is far more demanding than that of the teacher within the face-to-face environment. There is a demand for varying levels of competencies to be developed in order to manage and navigate the virtual classroom while developing techniques to facilitate learning within a virtual space. Stacey and Wilson (2004) outline the functions of the online educator as content and process facilitator, technologist, designer, manager, administrator, advisor, counselor, assessor, and researcher. Some institutions employ the use of competency frameworks to provide staff support for courseware use and designing course materials. This is not the reality for many developing countries, as resources are most times limited and, in some instances, as in the case of Open Campus, staffing is provided from different territories throughout the Caribbean region and persons involved in teaching are not required to interact. The implementation of strategies to encourage staff collaboration across an institution despite geographic location provides an opportunity for staff development (Kandlebinder, 2001). The initiation of peer teams allows for a considerable degree of accountability as faculty members are allowed to assess and evaluate individual methods. This aligns with Stacey and Wilson's (2004) principles of effective staff development where there is a focus on workplace practices while enabling the sharing and pooling of knowledge in keeping with institutional best practice ideologies.

Rogers' (1995) research on the adaptation of technology provides valuable insight into staff transition and development within the virtual teaching arena. While the primary scope of the research looks at staff diffusion into the technological teaching arena, its merit, as a guide to peer collaboration and evaluation for the teaching of English for Academic Purposes, is evidenced. The introduction of a peer team provides a forum to test the advantages of adopting one teaching strategy over another, compatibility of content and methods of delivery selected, complexity of strategies being employed and possible alternatives, 'trialability' of alternative strategies, and ultimate outcome of collaborative efforts (Donovan, 1999). Rogers (1995) also highlights the need for the teaching of instructional design skills as a component of web-based teaching and learning. Collaboration allows for the development of teaching skills, thus enriching faculty. Rankine, Sheely \& Veness (2001) attest to the complexity and high demands of online teaching. They point to the developed required skill level, as well as the required shift from viewing teaching as an isolated endeavor to one dependent on collective support teams, to ensure the authenticity of the learning experience. While adhering to these recommendations satisfies the functional delivery component of the teaching process, it neglects the operation of multiple facilitators functioning within individualized virtual environments in large courses offered to students. The support given needs to extend beyond the boundaries of navigating the virtual classroom to account for parity among educators as it relates to content, context and conceptualization. Scott and Miner (2008) see the formation of peer partnerships as providing the needed forum for collaboration and reflective dialogue.

In English for Academic Purposes, the selection and organization of material for course delivery is the responsibility of the course coordinator. Individual tutors have leverage only insofar as they adapt available material for their own specific class. The fact that tutors are chosen from different islands/territories across the Caribbean means that there is little opportunity to interact and share ideas, except as mediated through the Teachers' Forum in the online learning exchange. The online version of English for Academic Purposes consists of five assessments: 1) an online quiz, 2) an essay outline and an introductory paragraph, 3) a body paragraph developed from the outline, 4) a peer discussion, 5) a mini-essay. Students are expected to show competency in the expository methods taught: Analysis by Division, Classification, Cause and Effect Analysis, Process Analysis, and Extended Definition. Varying responses to student questions on course content and variation in the assessment of assignments, despite course rubrics, are indicative of a need to foster greater collaboration and exchange of ideas among staff. Collaboration focused on two aspects: 1) strategies to support tutor lesson planning for student participation in selected expository methods and 2) strategies to support standardization of tutor feedback to students.

\section{Research Questions}

As such, the research seeks to provide responses to the following questions: 
- Would pairing teachers on specific aspects of course content result in greater standardization of course content within the forum?

- What would be the impact of pairing teachers to work on specific aspects of course content on standardization of approaches to teaching?

- $\quad$ To what extent does peer collaboration result in the development of new, practical strategies for improving student learning within the online environment?

\section{RESEARCH METHODOLOGY}

The selection of strategies is influenced by the reflective practice model proposed by Bell (2002) and further theorized by Schon $(1983,1987)$ where the teacher evaluates his/her own skills, attitudes and knowledge with a view to improving practice. Accepting feedback from others is an important aspect of this transformative process. Steps proposed by Grey (1989) were also utilized as a model for structuring the online investigation.

\section{Initiating Research}

Using Scott and Miner (2008) as a guide, research was conducted to investigate the impact of structured peer evaluation/coaching on teaching, specifically in relation to lesson planning and execution. Collaboration was conducted over the course of one academic semester (13 weeks) in the following areas of preparation of lessons/presentations and assessments.

\section{Participants and Procedures}

Fourteen tutors are involved in the teaching of the online expository writing course English for Academic Purposes in semester 2. The assignation of group members was done by the course coordinator using the criteria of experience and competency; thus, an experienced tutor was paired with a tutor new to the online environment, or where the experience level of both members was the same, competency was applied; thus, a tutor who demonstrated competency in a certain area was paired with one who was less so. Partners had the responsibility of making contact with each other and deciding on the specific aspects of collaboration with regard to their assignment. Tutors were invited to use any medium to make their presentation - PowerPoint, bullet points, or case study. They were encouraged to use skype/email to make contact.

Each group was assigned a specific aspect of the course content/delivery to prepare. The aspects identified for collaboration were chosen based on traditional problem areas within course delivery. Each group was required to first make a presentation within the teachers' forum where the presentation would be critiqued before its adoption by the others for use within individual e-classes. This process of peer collaboration and presentation would take place over a 13-week semester with approximately one presentation per week. Each group was given a specific week for presentation. Each activity was completed and presented to peers a week prior to presentation within their respective student forums. Peers were invited to comment on each presentation and these suggestions, constructive critiquing and amendments were employed in the restricting/revising of teaching strategies. Table 1 details the group, the activity, and the material available.

Table 1: Activities Assigned to Peer Teams and Material Available for e-sessions

\begin{tabular}{|l|l|l|}
\hline Team & \multicolumn{1}{|c|}{ Activity } & \multicolumn{1}{c|}{ Material } \\
\hline 1 & Pointers for marking credit assignment 2 & $\begin{array}{l}\text { Rubric for marking thesis, outline, introduction and body } \\
\text { paragraph }\end{array}$ \\
\hline 2 & Sample activity process analysis & Course material and unit objectives \\
\hline 3 & Pointers for marking credit assignment 3 & Rubric for marking discussion \\
\hline 4 & Pointers for marking credit assignment 4 & Rubric for marking mini-essay \\
\hline 5 & Strategies for encouraging student participation & Forum guidelines \\
\hline 6 & Sample participation activity for cause and effect analysis & Course material and unit objectives \\
\hline 7 & Sample participation for extended definition & Course material and unit objectives \\
\hline
\end{tabular}


The outcome of the collaboration would be assessed on the following criteria:

- $\quad$ Clarity of objectives of assignment

- $\quad$ Practicality in terms of implementation within e-groups

- $\quad$ Presentation

- $\quad$ Relevance to course objectives

The study accepts that peer participation in this exercise is premised on a willingness to interrogate practice, coupled with an assumption of expected benefits and desirable outcomes. Forum posts to peer activity were also evaluated to gauge feedback to activity.

\section{FINDINGS}

Five teams were able to complete the activities in the specified time period, whereas two teams did not complete the assigned tasks. One group, after several false starts, had to be given a new assignment. One other group never presented or participated. Therefore, of the original tasks assigned, the following activities were completed: Pointers for Marking Credit Assignment 2 (Table 2); Pointers for Marking Credit Assignment 3 (Table 4); Pointers for Marking Credit Assignment 4 (Table 5); Strategies for Encouraging Student Participation (Table 6) and Sample Participation for Extended Definition (Table 8). The following activities were not completed by the assigned teams: Sample Participation Activity for Process Analysis (Table 3) and Sample Participation activity for Cause and Effect Analysis (Table 7). Findings are divided into results of the activity and general peer feedback.

Table 2: Activity 1 - Pointers for Marking Credit Assignment 2

\begin{tabular}{|l|l|l|}
\hline \multicolumn{1}{|c|}{ Objectives } & \multicolumn{1}{c|}{ Material Available } & \multicolumn{1}{c|}{ Adjustments Proposed } \\
\hline $\begin{array}{l}\text { To assess students' ability to } \\
\text { produce the required topic-to- } \\
\begin{array}{l}\text { sentence expository outline and a } \\
\text { related introductory and body } \\
\text { paragraph. }\end{array}\end{array}$ & $\begin{array}{l}\text { Rubric which details how each section } \\
\text { of the students' work is to be assessed. }\end{array}$ & $\begin{array}{l}\text { Retention of current objectives but more } \\
\text { specificity in defining criteria used to assess } \\
\text { assignments and the inclusion of a chart with } \\
\text { pointers on how to keep track of individual } \\
\text { student performance in each category (see } \\
\text { Appendix 1). }\end{array}$ \\
\hline
\end{tabular}

Table 3: Activity 2 - Sample Participation Activity for Process Analysis

\begin{tabular}{|l|l|l|}
\hline \multicolumn{1}{|c|}{ Objectives } & \multicolumn{1}{|c|}{ Material Available } & \multicolumn{1}{c|}{ Adjustments Proposed } \\
\hline $\begin{array}{l}\text { To encourage students to } \\
\text { consciously engage in } \\
\text { incorporating characteristics of } \\
\text { mode in their writing. }\end{array}$ & Course material on process analysis. & $\begin{array}{l}\text { No feedback. Team did not meet. Course } \\
\text { coordinator re-assigned team to another activity. }\end{array}$ \\
\hline
\end{tabular}

Table 4: Activity 3 - Pointers for Marking Credit Assignment 3 (Graded Discussion)

\begin{tabular}{|l|l|l|}
\hline \multicolumn{1}{|c|}{ Objectives } & \multicolumn{1}{|c|}{ Material Available } & \multicolumn{1}{c|}{ Adjustments Proposed } \\
\hline $\begin{array}{l}\text { To create an approach for tutors } \\
\text { to organize students effectively } \\
\text { for graded discussion and } \\
\text { subsequent tutor marking. }\end{array}$ & Grading rubric for assignment & $\begin{array}{l}\text { Development of a systematic approach to marking } \\
\text { assignment consisting of step-by-step guidelines } \\
\text { on identifying strengths and weaknesses of student } \\
\text { posts as well as a step-by-step guide to encourage } \\
\text { students to self-evaluate the quality of their } \\
\text { posting. }\end{array}$ \\
\hline
\end{tabular}

Table 5: Activity 4 - Pointers for Marking Credit Assignment 4 (Mini-essay)

\begin{tabular}{|l|l|l|}
\hline \multicolumn{1}{|c|}{ Objectives } & \multicolumn{1}{c|}{ Material Available } & \multicolumn{1}{c|}{ Adjustments Proposed } \\
\hline $\begin{array}{l}\text { To further standardize criteria } \\
\text { used by tutors to assess mini- } \\
\text { essay (introduction, two body } \\
\text { paragraphs and conclusion) }\end{array}$ & Grading rubric for assignment & $\begin{array}{l}\text { Further specificity of criteria for each section of } \\
\text { rubric. Incorporation of chart suggested in first } \\
\text { presentation. Further guidelines to students on } \\
\text { useful transitional devices and significance of } \\
\text { proofreading. }\end{array}$ \\
\hline
\end{tabular}


Table 6: Activity 5 - Strategies for Encouraging Student Participation

\begin{tabular}{|l|l|l|}
\hline \multicolumn{1}{|c|}{ Objectives } & \multicolumn{1}{|c|}{ Material Available } & \multicolumn{1}{c|}{ Adjustments Proposed } \\
\hline $\begin{array}{l}\text { To establish importance of tutor } \\
\text { encouragement of student } \\
\text { participation in online } \\
\text { environment. }\end{array}$ & $\begin{array}{l}\text { Course guidelines on encouraging } \\
\text { student participation. }\end{array}$ & $\begin{array}{l}\text { Presentation on benefits of participation for } \\
\text { students. Exploration of specific strategies that } \\
\text { tutors can use to encourage participation in forum. }\end{array}$ \\
\hline
\end{tabular}

Table 7: Activity 6 - Sample Participation Activity for Cause and Effect Analysis

\begin{tabular}{|l|l|l|}
\hline \multicolumn{1}{|c|}{ Objectives } & \multicolumn{1}{|c|}{ Material Available } & \multicolumn{1}{c|}{ Adjustments Proposed } \\
\hline $\begin{array}{l}\text { To encourage students to } \\
\text { consciously engage in } \\
\text { incorporating characteristics of } \\
\text { mode in their writing. }\end{array}$ & $\begin{array}{l}\text { Course material on Cause and Effect } \\
\text { Analysis }\end{array}$ & $\begin{array}{l}\text { Team assigned did not participate in this activity. } \\
\text { Cited technical difficulties in contacting each } \\
\text { other. }\end{array}$ \\
\hline
\end{tabular}

Table 8: Activity 7 - Sample Participation Activity for Extended Definition*

\begin{tabular}{|l|l|l|}
\hline \multicolumn{1}{|c|}{ Objectives } & \multicolumn{1}{|c|}{ Material Available } & \multicolumn{1}{c|}{ Adjustments Proposed } \\
\hline $\begin{array}{l}\text { To create opportunities for } \\
\text { students to demonstrate } \\
\text { competency in using Extended } \\
\begin{array}{l}\text { Definition } \\
\end{array}\end{array}$ & $\begin{array}{l}\text { Course material on Extended } \\
\text { Definition }\end{array}$ & $\begin{array}{l}\text { Team 1: Use of case study - each student studies } \\
\text { case and formulate expository response. } \\
\text { Team 2: Form online teams where students work } \\
\text { together on given topics to produce an extended } \\
\text { definition essay. (See Appendix 2) }\end{array}$ \\
\hline
\end{tabular}

\section{Peer Feedback on Collaboration}

Figure 2 displays tutor/peer feedback based on forum posts on collaborative effort within the forum:

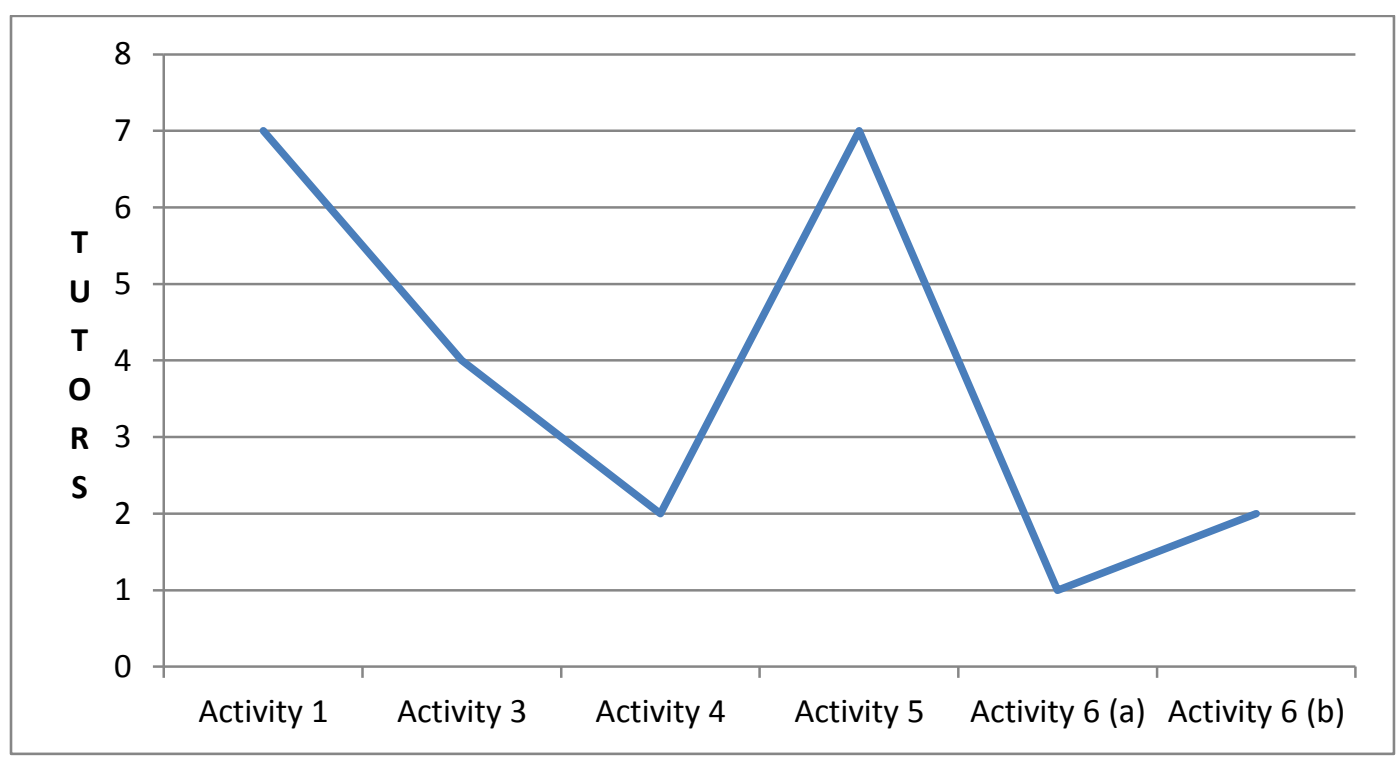

Figure 2: Frequency of Tutor Feedback on Assigned Activities

Of the 14 tutors within the course, 7 responded with comments on the first activity, 4 responded on Activity 3, 2 on Activity 4, 7 on activity 5, 1 on Activity 6 (a) (case study), and 2 on Activity 6 (b) (group activity). The two activities with the highest feedback were Activities 1 and 5 which addressed the assessment of Credit Activity 2 and the issue of student participation. 


\section{A FUTURE FOR PEER EVALUATION WITHIN THE ONLINE LEARNING ENVIRONMENT: CONCLUSION}

Peer collaboration identified specific areas that needed improvement in course delivery, in general, and individual practice, in particular. This was evident in Activity 1, for example, where standards already provided are expanded for greater clarity. The activities demonstrated a greater degree of self-assessment (Boud, 1991) as the construction of questions required the use of higher order cognitive competencies and greater understanding of subject content. The need to work together encouraged peers to self-reflect on understandings of course material, as well as critically assess contributions to ensure that objectives were being achieved. The activities revealed a clearer understanding of the proficiencies required to meet the criteria and standards of the course.

\section{Lack of Collaboration}

One team - or two tutors - did not participate in the collaborative activity at all, either by way of posting comments or in producing the anticipated activity. Poor communication via email was cited as the main reason. The belief is held that skepticism about the implementation of peer teams could also have been a factor. This skepticism can be resolved over time as perceptions change about judgments on peer collaboration. On the positive side, collaborative work fostered personal acknowledgements of strength and weaknesses, essentially resulting in improved quality output. On the other hand, fluctuations in feedback on peer collaboration show that even within the online environment, peers seemed unwilling to comment on the work of others. Of the 14 assigned tutors, 7 remained the highest figure for peer feedback within the forum, with the most feedback obtained on Credit Assignment 2, which is the first assignment that tutors have to mark (Credit Assignment 1 being a quiz), and Activity 5, which addressed the issue of student participation - a major concern within the online environment. Increasing pressures of marking, as well as lack of interest in the topic, could have influenced fluctuating levels of tutor feedback.

\section{Revising Collaboration}

Another implication for peer collaboration is the rotation of peer activities which ensures that the 'standard' continues to improve while also allowing for the incorporation on improvements and changes in the field. It may also assist in minimizing conflict where peers do not work well together, which the findings show can also be an issue in the online environment. There is also the need to involve more practitioners in the construction of activities as there is the risk of staff becoming complacent and unhealthy dependence being fostered where activities are accepted and implemented out of expediency. Larger teams suggest the presentation of more perspectives about the importance of criteria and the validity of the end product. This remains a viable area for future research which, however, is impacted by the constraints of high administrative and academic demands.

\section{Support for Peer Learning}

The need for practitioners to be acknowledged as active participants in the learning process is echoed throughout the study. Not only did the study reveal the significant benefits of implementing collaborative forums, it also points to its usefulness as a Personal Development Planning tool (William \& Ryan, 2003). The collaborations demonstrated engagement in structured, integrated and strategic processes geared towards providing an actionable direction for the improvement of teaching and learning. The benefits of this can be transferred to other areas of practice. The collaboration resulted in teaching didacticism and the design of activities with improved skill focus.

The study also points to further research into the implementation of collaborative teams within the face-toface environment as a strategy to address issues of territorialism and professional identity. It foregrounds investigation into the merit of teaching partnerships in other academic writing programmes as well as the impact on student output. Comparative analysis can also be conducted to examine the impact of collaborative teams in the virtual and face-to-face environment for the same programme. 


\section{AUTHOR INFORMATION}

Karen Sanderson Cole is a graduate of the University of the West Indies. She holds a B.A (Hist, Lang and Lit), an M.Phil (Literatures in English); a post-graduate diploma in Education and a Masters of Higher Education in Teaching and Learning at the Tertiary Level. She is currently a PhD. candidate at the University of the West Indies, where she also serves as an academic staff member. Her research interests include, but are not limited to, transformations in the teaching of academic writing, e-pedagogy, assessment in higher education and theoretical underpinnings in Caribbean literature. E-mail: Karen.sanderson-cole@sta.uwi.edu

Danielle Watson is a graduate of the University of the West Indies, with a Bachelor's degree in Literatures in English and Linguistics and a Masters of Higher Education (MHEd) in Tertiary Teaching and Learning. She is currently a PhD Linguistics candidate at the University of the West Indies, where she is also involved in the coordination of writing programmes designed to assist students at the tertiary level. Her research interests are in the areas of programme design and evaluation at the tertiary level, tertiary teaching and learning in the Caribbean and language ideologies. E-mail: danielle.watson@ sta.uwi.edu (Corresponding author)

\section{REFERENCES}

1. Austin, A., \& Baldwin, R. (1992). Faculty collaboration: Enhancing the quality of scholarship and teaching. ERIC Digest. Eric Clearinghouse on Higher Education. Washington D.C. School of Education and Human Development.

2. Bell, M. (2002). Peer observation of teaching in Australia. Australia: Centre for Educational Development and Interactive Resources at the University of Wollongong.

3. Boud, D. (1991). Implementing students self-assessment, ( ${ }^{\text {nd }}$ ed) Green Guide no.5, Higher Education Research and Development Society of Australia.

4. Cordingley, P., Bell, M., Rundell, B. \& Evans, D. (2003). The impact of collaborative CPD on classroom teaching and learning. In: Research evidence in education library. version 1.1. London: EPPI-Centre, Social Science Research Unit, Institute of Education.

5. Dalton, S., \& Moir, E. (1991). "Evaluating LEP teacher training and n-service programs." Paper presented at the Second National Research Symposium on Limited English Proficient Student Issues. Washington, DC.

6. Donovan, M. (1999). Rethinking faculty support: The Technology Source. (September/October 1999).

7. Francis, J., \& Buckley, S. (1999). Team teaching: What, why and how? University of San Francisco: Sage Publication.

8. Grey, B. (1989) Collaborating: Finding common ground for multiparty problems. San Francisco: Jossey-Bass.

9. Hinett, K., \& Thomas, J. (1999). Staff guide to self and peer assessment. Headington, Oxford: The Oxford Centre for Staff \& Learning Development.

10. Joyce, B., \& Showers, B. (1980). “Improving In-service Training: The Messages of Research.” Educational Leadership 37, 5: 379 - 385.

11. Kandlbinder, P. (2001). Peeking under the covers: Understanding the foundations of online academic staff development. Paper presented at the ASET/HERSA 2000 Flexible Learning for a Flexible Society (July 25, 2000). University of Southern Queenland, Toowoomba, Australia.

12. Rankine. L., S. Sheely \& D. Veness. (2001). Building the web interactive study environment: Mainstreaming online teaching and learning at the University of Western Sydney. Australian Journal of Educational Technology. 17(1), 80-95.

13. Rogers, E. M. (1995). Diffusion of innovations $\left(4^{\text {th }}\right.$ ed). New York: The Free Press.

14. Roschelle, J. \& Pea, R. (1999). Trajectories from today's WWW to a powerful educational infrastructure. Educational Researcher, 43, 22-25.

15. Ryan, S., \& Williams, S. (2003). Experiences of delivering guidance on personal development planning for undergraduates: An exploration of academic advisers as role models. Scholarship of Learning and Teaching (SoLT) Research Project, University of Gloucestershire, England.

16. Schön, D. (1983). The Reflective practitioner. Basic Books: New York.

17. Schön, D. (1987). Educating the reflective practitioner. Jossey-Bass: San Francisco. 
18. Scott, V., \& Miner, C. (2008). "Peer coaching: Implications for teaching and program improvement". Transformative dialogues: Teaching and learning journal, 1 (3).

19. Stacey, E. \& Wilson, G. (2004). Online interaction impacts on learning: Teaching the teachers to teach online. Australasian Journal of Educational Technology 2004, 20(1), 33-48.

20. Stuckey, B., Lockyer, L., \& Hedberg, J. (2001). The case for community: On-line and ongoing professional support for communities of practice. Paper presented at the Open and Distance Learning Association of Australia (ODLAA) $15^{\text {th }}$ Biennial Forum (September 24-27, 2001). Sydney, New South Wales, Australia.

21. Tchantz, J.M., \& Vail, C.O. (2000). Effects of peer coaching on the rate of responsive teacher statements during a child-directed period in an inclusive preschool setting. Teacher and Special Education, 23, 189201.

22. Vacilotto, S., \& Cummings, R. (2007). Peer coaching in TEFL/TESL Programmes. ELT Journal, 61(2), 153-160.

23. Waller, S. (2004). Conflict in higher education faculty evaluation: An organizational perspective. Organizational Issues and Insights, New Foundations: Supporting the Reflective Educator.

24. Wilson, G., \& Stacey, E. (2004). Online interaction impacts on learning: Teaching the teachers to teach online. Australasian journal of educational technology. 2004, 20(1), 33-48. 


\section{APPENDIX 1: POINTERS FOR MARKING CREDIT ASSIGNMENT 2}

The peer team suggested amending the guidelines as follows:

\begin{tabular}{|c|c|}
\hline Available Criteria & Suggested Criteria for Assessment (Table 2) \\
\hline Analysis by Division/Classification & Analysis by Division \\
\hline $\begin{array}{l}\text { Thesis Statement } \\
\text { - Thesis succinct } \\
\text { Indicate the three-four } \\
\text { main points to be } \\
\text { developed in the body } \\
\text { No provision for this on } \\
\text { rubric }\end{array}$ & $\begin{array}{l}\text { Thesis Statement } \\
\text { - Thesis should be one sentence that does not run on } \\
\text { - Indicate the divisions of the topic to be explored in the body paragraphs (3-4) } \\
\text { - Utilize words/phrases that reflect division, e.g., consists of, components }\end{array}$ \\
\hline $\begin{array}{ll}\text { Body of Outline } \\
\text { - } & \text { Topic to sentence format } \\
\text { - } & 3-4 \text { main points } \\
\text { - } & \text { Relevance to thesis } \\
& \text { statement and overall } \\
& \text { question }\end{array}$ & $\begin{array}{l}\text { Body of Outline } \\
\text { - Follow the pattern of a topic to sentence outline } \\
\text { - Consist of the topics/divisions indicated in the thesis statement (3or 4) } \\
\text { Consist of topic sentences that encapsulate the essay topic/ narrowed focus, the } \\
\text { transitions. } \\
\text { Classification } \\
\text { Thesis Statement } \\
\text { - Same as above except that thesis should indicate classification words such as } \\
\text { classes, groupings, categories, types } \\
\text { Body of Outline } \\
\text { - Same as above except that outline should consist of topics/categories listed in } \\
\text { the thesis statement } \\
\text { Consist of topic sentences that indicate the essay topic, the topics/categories to } \\
\text { be explored in the body paragraphs and appropriate transitions }\end{array}$ \\
\hline \multicolumn{2}{|r|}{ Marking the Introduction and the Body Paragraph } \\
\hline Available Criteria & Suggested Criteria \\
\hline $\begin{aligned} & \text { Introductory Paragraph } \\
& \text { - } \text { Establish relevant context } \\
& \text { for question } \\
& \text { - } \text { Lead logically into thesis } \\
& \text { statement } \\
& \text { - } \text { Grammatically sound } \\
& \text { Body Paragraph } \\
& \text { - } \\
& \text { Begins with main point in } \\
& \text { outline } \\
& \text { Develops point with } \\
& \text { examples and explanation } \\
& \text { Reflects overall } \\
& \text { organizational pattern } \\
& \text { required } \\
& \text { Reflects evidence of } \\
& \text { academic research }\end{aligned}$ & $\begin{array}{l}\text { Body Paragraph } \\
\text { - Begins with a topic sentence from the outline } \\
\text { - Details which explain/describe the topic (division/classification) in the topic } \\
\text { sentence in a logical and coherent manner. Appropriate word bridges should be } \\
\text { used to move from one example to another within the paragraph } \\
\text { - Consist of only relevant details, thus creating a unified paragraph } \\
\text { - } \text { Consist of a sentence that effectively closes the paragraph } \\
\text { - Grame a formal tone } \\
\text { - Shows evidence of research (in-text citations APA/MLA documentation style) }\end{array}$ \\
\hline
\end{tabular}




\section{APPENDIX 2: SAMPLE PARTICIPATION ACTIVITY EXTENDED DEFINITION}

New Pointers:

- Use a chart with a list of names of all the students in each group. Within that chart, you will have space for result of the topic-to-sentence outline and the thesis statement for each student. Make a note of the strong points or shortcomings to remember to include those in the feedback.

- $\quad$ For the justification, give one mark if the method is not fully justified. Note that certain key words need to be used. If analysis by division, then the idea of breaking down points into smaller components in order to analyze them, should be clear. If classification, then the concept of grouping according to commonality or association should be clear. 